\title{
ESTRATÉGIAS PROMOCIONAIS UTILIZADAS POR ESCRITÓRIOS DE CONTABILIDADE DE TANGARÁ DA SERRA-MT PARA ATRAIR CLIENTES
}

\author{
Danielli Gonçalves da Cunha ${ }^{1}$ \\ Silvio Melo Gonçalves ${ }^{2}$
}

\begin{abstract}
RESUMO
A pesquisa teve como objetivo conhecer as estratégias promocionais utilizadas pelos escritórios de contabilidade de Tangará da Serra-MT para atrair clientes. Para se chegar aos resultados, foram utilizadas pesquisas bibliográficas sobre o tema abordado e aplicação de questionário aos contadores para saber sua opinião sobre o uso do marketing e identificar quais estratégias eles utilizam para promover seus escritórios. A aplicação do questionário foi realizada entre os meses de Março e Abril de 2012 em 29 escritórios da cidade. O questionário continha 16 questões acerca do perfil do contador, nele foram identificados os principais serviços oferecidos pelos escritórios, à opinião dos empresários sobre a importância da propaganda neste ramo e as principais estratégias utilizadas para atrair clientes. Foi concluída, através do questionário, que a principal estratégia promocional utilizada pelos escritórios é a confecção de brindes, os entrevistados acreditam que a exposição destes materiais nas empresas de seus clientes pode atrair novos clientes para seus escritórios, além da propaganda feita através do famoso "boca-boca", que segundo eles, também é de grande importância nesse ramo.
\end{abstract}

Palavras-chave: Contadores. Marketing de serviços. Comunicação. Propaganda.

\section{INTRODUÇÃO}

A pesquisa a seguir trata da análise das estratégias promocionais utilizadas pelos escritórios de contabilidade para atrair clientes na cidade de Tangará da Serra-MT, através da captação de dados pertinentes ao tema por aplicação de questionário.

O papel do contador junto aos seus usuários mudou consideravelmente nos últimos anos. A importância do profissional contábil em uma organização é relevante, porém não muito difundida. Quebrar certos conceitos sobre a profissão e expor as novas aplicações da contabilidade, agrega valor aos serviços e melhora a qualidade de vida do próprio profissional, tendo seu trabalho recebido com a consideração que lhe merecida.

Conhecer as necessidades de seus clientes, e atendê-las com qualidade é de essencial importância para a manutenção da participação no mercado, assim como apresentar corretamente seus serviços, incluindo diferenciais, traz a inclinação dos consumidores a contratarem o que é proposto.

\footnotetext{
1 Acadêmica do curso de Ciências Contábeis da UNEMAT- Campus de Tangará da Serra, e-mail: danicunha_tga@hotmail.com

${ }^{2}$ Professor do curso de Ciências Contábeis e Administração da UNEMAT- Campus de Tangará da Serra, e-mail: silvio.tga@gmail.com 
Estratégias promocionais utilizadas por escritórios de contabilidade de Tangará da Serra-MT para atrair clientes

Danielli Gonçalves da Cunha

Silvio Melo Gonçalves

Logo, este artigo teve como problema: "Estratégias promocionais utilizadas por escritórios de contabilidade de Tangará da Serra-MT para atrair clientes”.

As hipóteses levantadas para o desenvolvimento dessa pesquisa e para a resolução do problema foram:

H1- Os escritórios contábeis utilizam-se dos meios de comunicação para promoção de seus serviços.

H2- Os escritórios de contabilidade não possuem estratégias promocionais.

A presente pesquisa objetivou verificar quais estratégias promocionais eram utilizadas por escritórios de contabilidade da cidade de Tangará da Serra-MT para atrair clientes.

Para se chegar ao objetivo geral, foram realizadas pesquisas bibliográficas sobre o assunto abordado, levantamento junto à Secretaria de Fazenda (SEFAZ-Municipal) sobre o número e localização dos escritórios contábeis existentes em Tangará da Serra-MT e aplicação de questionários a alguns empresários do ramo da contabilidade, para que se pudesse analisar de que forma os escritórios contábeis divulgam seus serviços no mercado e verificar se eles possuíam alguma estratégia promocional concreta.

A organização contábil tem grande importância na economia do país, pois a mesma possui boa parte da responsabilidade pelo sucesso ou fracasso da empresa. É a partir daí que entra o marketing contábil, que tem a função de apresentar os serviços prestados e expor a qualidade desses serviços, mostrando para o cliente que a contabilidade é peça fundamental para o sucesso de sua empresa.

Com a realização desta pesquisa pôde-se ter visão mais ampla de como o empresário contábil vê o marketing, e também mostrá-lo a importância de se investir em propaganda para maior reconhecimento de seus serviços no mercado. Assim como também, mostrar à sociedade a importância dos trabalhos desenvolvidos pelos escritórios de contabilidade, que muitas vezes são desconhecidos por estes pela falta de divulgação.

Para a Universidade, a pesquisa veio demonstrar quais estratégias promocionais são utilizadas por escritórios contábeis para atrair clientes e para maior reconhecimento de seus serviços no mercado, além de evidenciar a importância de duas disciplinas: O Marketing e a Contabilidade. Para o autor do artigo, a pesquisa foi de grande importância, já que proporcionou conhecimento mais amplo tanto sobre a contabilidade, quanto sobre o uso do marketing. Através do questionário aplicado, puderam-se obter informações precisas das estratégias promocionais utilizadas por escritórios de contabilidade do município de Tangará da Serra-MT. 


\title{
2. REFENCIAL TEÓRICO
}

\subsection{MARKETING}

Observar as necessidades dos consumidores, apontar a importância de inserção de produto ou serviço no mercado e acompanhar os processos que englobam a troca de produtos e valores, buscando sempre a satisfação das necessidades do indivíduo, são alguns dos papéis do marketing.

De acordo com Blessa (2001, p.17), o marketing pode ser definido assim:

Processo de planejamento, execução, preço, comunicação e distribuição de idéias, bens e serviços, de modo a criar trocas (comercio) que satisfaçam aos objetivos individuais e organizacionais. A ação de marketing é mais ou menos ampla, conforme o enfoque de cada empresa.

Ainda, segundo Kotler e Armstrong (2003, p.3), o marketing é "um processo administrativo e social pelo qual indivíduos e grupos obtêm o que necessitam e desejam, por meio da criação, oferta e troca de produtos e valor com os outros".

Sendo assim, Kotler e Armstrong (2003, p.3) salientam que:

\begin{abstract}
Hoje em dia, o marketing não deve ser compreendido apenas no antigo sentido de fazer uma venda - "dizer e vender"- mas também no novo sentido de satisfazer as necessidades do cliente. Se um profissional de marketing fizer um bom trabalho de identificação dessas necessidades, desenvolver produtos de valor superior apreçá-los distribui-los e promovê-los eficientemente, esses produtos serão vendidos com muita facilidade.
\end{abstract}

Diante de tantos procedimentos surge à necessidade de administração eficiente, é nesse ponto que entra a Administração de Marketing, que tem a função de controlar as vendas dos produtos e serviços, analisar os resultados obtidos com essas vendas bem como a satisfação dos clientes e observar as novas necessidades dos consumidores, a fim de realizar mudanças para que a empresa continue alcançando lucros.

Essa administração de marketing é definida por Kotler e Armstrong (2003, p.8) como:

[...] a análise, planejamento, implementação e controle de programas concebidos para criar, desenvolver e manter trocas benéficas com os compradores-alvo a fim de atingir objetivos organizacionais. Portanto, a administração de marketing envolve administrar a demanda, que por sua vez envolve administrar relacionamentos com o cliente.

Segundo Las Casas (1994, p.38) a administração de marketing "é uma ciência normativa que envolve criação e oferta de valores para estimular a transação desejada".

Sendo assim, a atividade de um administrador de marketing não é só planejar, organizar, controlar e executar, mas também tem a função de colher informações em seu ambiente e adaptá-las conforme as necessidades e desejos dos consumidores. 


\subsection{COMPOSTO DE MARKETING}

Para que a empresa possa comercializar seus produtos e serviços é necessário levar em conta quatro variáveis importantes, conhecidas também como 4'Ps: produto, preço, praça e promoção. Essas quatro variáveis que são utilizadas em qualquer comercialização formam o chamado composto de marketing.

Las Casas (2001, p.18-19) salienta que "quando o administrador planejar todos os subitens dos quatro grupos de acordo com o objetivo de comercialização, ele terá o composto de marketing planejado".

Dentro do composto de marketing temos o chamado Mix de comunicação de marketing, que é composto de cinco formas de comunicação essenciais para o sucesso de uma empresa: Propaganda; Promoção de vendas; Relações públicas e publicidade; e Vendas pessoais e Marketing direto.

Kotler (2000, p.584-585) traz a definição para essas cinco formas de promoção:

1. Propaganda: qualquer forma paga de apresentação e promoção não-pessoais de idéias, mercadorias ou serviços por um anunciante identificado.

2. Promoção de vendas: uma variedade de incentivos de curto prazo para encorajar a experimentação ou a compra de um produto ou serviço.

3. Relações públicas e publicidade: uma variedade de programas elaborados para promover ou proteger a imagem de uma empresa ou de seus produtos.

4. Vendas pessoais: interação pessoal (cara a cara) com um ou mais compradores potenciais visando apresentar produtos ou serviços, responder perguntas e tirar pedidos.

5. Marketing direto: utilização de correio, telefone, fax, e-mail ou internet para se comunicar diretamente com clientes específicos e potenciais ou lhes solicitar uma resposta direta.

Com base nessas formas de comunicação o empresário pode escolher a que melhor se encaixa dentro de sua empresa. Na propaganda, pode optar por realizar anúncios impressos e eletrônicos, cartazes e folhetos, outdoors, material audiovisual, manuais e brochuras, entre outros. Na promoção de vendas pode conceder prêmios e presentes, exposições e concessões de troca. Em relações públicas, investir em palestras, patrocínios e doações. Nas vendas 
Estratégias promocionais utilizadas por escritórios de contabilidade de Tangará da Serra-MT para atrair clientes

Danielli Gonçalves da Cunha

Silvio Melo Gonçalves

pessoais pode apostar em feiras e exposições e no marketing direto investir em catálogos, vendas por meio da televisão e e-mail.

Kotler (2000, p.606) destaca no quadro1 abaixo as principais estratégias promocionais, suas vantagens e limitações.

Quadro 1: Perfil dos principais tipos de propaganda

\begin{tabular}{|c|c|c|}
\hline MEIO & VANTAGENS & LIMITAÇÕES \\
\hline Jornais & $\begin{array}{l}\text { Flexibilidade, oportunidade, boa } \\
\text { cobertura de mercado local, } \\
\text { ampla aceitação, alta } \\
\text { credibilidade. }\end{array}$ & $\begin{array}{l}\text { Vida curta, baixo nível de } \\
\text { qualidade de reprodução, } \\
\text { pequeno público circulante. }\end{array}$ \\
\hline Televisão & $\begin{array}{l}\text { Combina visão, } \\
\text { movimento; apela para os } \\
\text { sentidos; alta repetição; alta } \\
\text { cobertura. }\end{array}$ & $\begin{array}{l}\text { Custo absoluto alto, saturação de } \\
\text { comunicação elevada, exposição } \\
\text { transitória, menor grau de } \\
\text { seletividade do público. }\end{array}$ \\
\hline Mala direta & $\begin{array}{l}\text { Seletividade de público, } \\
\text { flexibilidade, ausência de } \\
\text { concorrência dentro do mesmo } \\
\text { veículo, personalização. }\end{array}$ & $\begin{array}{l}\text { Custo relativamente alto, } \\
\text { imagem de "correspondência } \\
\text { inútil". }\end{array}$ \\
\hline Rádio & $\begin{array}{l}\text { Uso da massa, alto grau de } \\
\text { seletividade geográfica } \\
\text { demográfica, baixo custo. }\end{array}$ & $\begin{array}{l}\text { Apresentação sonora apenas, } \\
\text { menor grau de atenção do que a } \\
\text { televisão, tarifas não tabeladas, } \\
\text { exposição transitória. }\end{array}$ \\
\hline Revistas & 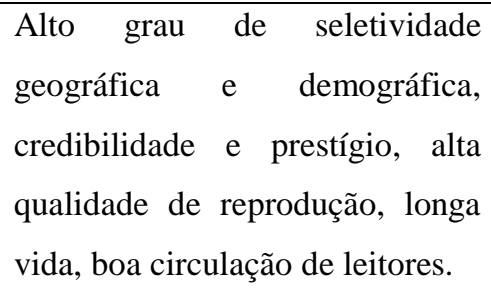 & $\begin{array}{l}\text { O espaço precisa ser comprado } \\
\text { com muita antecedência, certo } \\
\text { desperdício de circulação, } \\
\text { nenhuma garantia de posição. }\end{array}$ \\
\hline Outdoor & $\begin{array}{l}\text { Flexibilidade, alto grau de } \\
\text { repetição de exposição, baixo } \\
\text { custo, baixa concorrência. }\end{array}$ & $\begin{array}{l}\text { Seletividade de público limitada, } \\
\text { limitações criativas. }\end{array}$ \\
\hline Brochura/Folder & $\begin{array}{l}\text { Flexibilidade, controle total } \\
\text { mensagens de maior impacto. }\end{array}$ & $\begin{array}{l}\text { A produção excessiva pode levar } \\
\text { ao descontrole dos custos }\end{array}$ \\
\hline Telefone & $\begin{array}{l}\text { Muitos usuários, oportunidade de } \\
\text { dar um toque pessoal. }\end{array}$ & $\begin{array}{l}\text { Custo relativo alto, a não ser que } \\
\text { conte com voluntários. }\end{array}$ \\
\hline Internet & $\begin{array}{l}\text { Alta seletividade, possibilidades } \\
\text { interativas, custo relativamente } \\
\text { baixo. }\end{array}$ & $\begin{array}{l}\text { Veículo relativamente novo com } \\
\text { um pequeno número de usuários } \\
\text { em alguns países. }\end{array}$ \\
\hline
\end{tabular}

Fonte: Livro Administração de Marketing: a edição do Novo Milênio. Philip Kotler, 2000. 
Outro método de promoção, que não foi citado acima, mas que é de grande valia, é a indicação, que é feita de clientes da empresa para outros consumidores. Um cliente satisfeito não só continua comprando da mesma empresa, mas também serve como anúncios ambulantes.

Diante de tantas opções de divulgação cabe ao empresário escolher a que melhor se adequa a sua situação, não deixando de sempre observar as necessidades de seus clientes.

\section{O MARKETING E A CONTABILIDADE}

O marketing, em todas as áreas de atuação profissional, traz benefícios para quem o utiliza. É através dele que se define pontos importantes para um bom resultado nos negócios, tais como o perfil do cliente, suas necessidades, como apresentar seus produtos ou serviços no mercado e qual a satisfação dos usuários. Na contabilidade não poderia ser diferente, apesar de não muito utilizado nessa área, o marketing pode se tornar um auxílio para os empresários que buscam consolidar a marca de sua empresa contábil no mercado de trabalho.

Bertozzi (2003 apud PELEIAS et al, 2007, p.65) define o marketing contábil como:

São todos os esforços estratégicos e comunicacionais para ofertar serviços de qualidade, criados para suprir a necessidade e desejos do cliente, utilizando os instrumentos de marketing, sempre de acordo com a ética. $\mathrm{O}$ marketing contábil bem realizado deve na realidade, influir como os clientes percebem o profissional, o escritório, e essa percepção é que irá gerar uma imagem positiva ou negativa. $\mathrm{O}$ contabilista deve construir uma marca pessoal universal.

Para concluir Peleias et al (2007, p.65) ressalta que:

O contador empresário que busca o sucesso profissional precisa desenvolver sua marca pessoal em torno da imagem positiva. Precisa elaborar e oferecer produtos e serviços diferenciados, identificar e entender as necessidades dos clientes, e estar atualizado com as perspectivas e tendências do mercado em que o cliente atua.

O CFC (1997), em relação aos deveres do profissional contábil quanto aos colegas de profissão discorre que "A conduta do Contabilista com relação aos colegas deve ser pautada nos princípios de consideração, respeito, apreço e solidariedade, em consonância com os postulados de harmonia da classe".

O Código de ética do profissional contábil ainda cita que o contabilista deve abster-se de fazer referências prejudiciais ou de qualquer modo desabonadoras em relação aos colegas da classe (CFC, 1997).

Entende-se, portanto que, o marketing, quando direcionado à prestação de serviços contábeis, requer cuidados para que o código de ética da profissão não seja ferido, nunca deve ser feito no intuito de denegrir a imagem de outro profissional ou empresa contábil. 


\section{MARKETING DE SERVIÇOS}

Segundo Lovelock e Wright (2003, p.5) o serviço pode ser definido da seguinte forma: "um ato ou desempenho oferecido por uma parte ou outra. Embora o processo possa estar ligado a um produto físico o desempenho é essencialmente intangível e normalmente não resulta em propriedade de nenhum dos fatores de produção". Ainda sobre serviços continuam, "são atividades econômicas que criam valor e fornecem benefícios para clientes em tempos e lugares específicos [...]".

Já para Las Casas (2002, p.17) os serviços “constituem uma transação realizada por uma empresa ou por um indivíduo, cujo objetivo não está associado à transferência de um bem". Analisando todas essas definições, entende-se que os serviços são vantagens ou satisfações que são oferecidas à venda.

O marketing de serviços tem a função de desenvolver a promoção dos serviços prestados por uma empresa e investigar as oportunidades no mercado, para que se possam oferecer serviços de qualidade. De certa forma, o marketing tem a função de indicar a forma de atingir o mercado e elaborar ofertas de serviços.

O marketing é dividido em cinco categorias de ofertas distintas, são elas:

- Bem tangível: consiste na oferta de um bem tangível, onde não existe nenhum tipo de serviço associado ao produto (exemplo: sabão).

- Bem tangível associado a serviços: consiste na oferta de um bem tangível que está associada a um ou mais serviços (exemplo: carros e computadores).

- Híbrida: onde ocorre a oferta tanto de bens como de serviços (exemplo: restaurantes, onde oferece a refeição e o serviço).

- Serviço principal associado a bens ou serviços secundários: é a oferta de um serviço principal com outros serviços adicionais inclusos (exemplo: companhias aéreas, que além de oferecer o transporte, também oferece outros serviços no interior da aeronave).

- Serviço puro: é a oferta de um serviço especificamente (exemplo: massagem).

Diante dessas categorias, os produtos possuem algumas generalizações e podem ser baseados em equipamentos e pessoas, Kotler (2000, p.449) "Os serviços baseados em pessoas podem ser divididos entre os que não requerem nenhuma qualificação, os que requerem alguma qualificação e os que exigem uma especialização.” Existem também os serviços que 
Estratégias promocionais utilizadas por escritórios de contabilidade de Tangará da Serra-MT para atrair clientes

Danielli Gonçalves da Cunha

Silvio Melo Gonçalves

necessitam da presença do cliente e outros que não, se a presença do cliente se faz necessária durante a realização do serviço é importante que o prestador conheça suas necessidades.

Em Kotler (2000, p. 449) diz que "os serviços diferem quanto ao tipo de atendimento das necessidades. Há serviços que atendem a uma necessidade pessoal e outros que atendem a uma necessidade empresarial." Com relação a esse caso, um exemplo é o atendimento médico, onde o atendimento e preço podem ser diferenciados para pacientes particulares e funcionários de uma determinada empresa que possua plano de saúde.

Os serviços possuem quatro características que contribuem para a elaboração de marketing, são elas:

- Intangibilidade: são produtos que não podem ser vistos, sentidos, ouvidos ou provados antes de serem adquiridos. (Kotler 2000, p.460)

- Inseparabilidade: onde os serviços e produtos são produzidos e consumidos simultaneamente.

- Variabilidade: os serviços são variáveis, pois dependem de quem os fornece, de onde e quando são fornecidos.

- Perecibilidade: os serviços não devem ser estocados, ou seja, devem-se elaborar estratégias para que o serviço seja consumido e não perca valor.

Dentro do conceito de satisfação do cliente, ainda se faz necessário o uso de algumas alternativas para conquistar o cliente e se manter no mercado, dentre elas se destacam:

- Oferta: as ofertas devem incluir características inovadoras, Kotler (2000, p.458) diz que, "O maior desafio é o fato de as inovações mais importantes no setor de serviços serem facilmente copiados. Porém, a empresa que introduzir inovações regularmente alcançará uma sucessão de vantagens" [...]. O importante aqui é buscar um diferencial com relação ao mercado, o empresário deve criar meios para se destacar e assim atrair novos clientes.

- Entrega: a empresa pode buscar pessoas qualificadas e treinar as que já têm para a execução dos serviços. Além de criar um processo de entrega mais eficaz e melhor do que o de seus concorrentes.

- Imagem: a empresa pode modificar a imagem de sua empresa através de símbolos e logotipos, buscando atrair clientes através do visual.

O mercado é bastante competitivo e para ganhar destaque dentro do mesmo é de grande importância que as empresas busquem se diferenciar, e essa diferença pode ser feita através da qualidade, da produtividade e do pós-vendas. 
Estratégias promocionais utilizadas por escritórios de contabilidade de Tangará da Serra-MT para atrair clientes

Danielli Gonçalves da Cunha

Silvio Melo Gonçalves

Segundo Kotler (2000, p.459) "Uma empresa prestadora de serviços pode sair ganhando ao executar um serviço com qualidade consistentemente superior à da concorrência e superar as expectativas dos clientes". Muitas pessoas se frustram com o serviço prestado por algumas empresas, pois nem sempre o que foi proposto é superado na prática, dessa forma o cliente vai procurar outra empresa e é nesse momento que a empresa que investir em qualidade terá maior sucesso.

No ponto da produtividade, entre os passos para o sucesso, destacam-se as empresas que investem na qualificação de seus funcionários, aumentam a quantidade de serviços sem modificar a qualidade, industrializar os serviços, desenvolver serviço mais eficaz, incentivar os clientes a optarem pelos seus serviços e usar da tecnologia para oferecer um melhor atendimento a seus clientes e conseqüentemente tornar seus funcionários mais produtivos.

$\mathrm{Na}$ área de pós-vendas, a empresa prestadora de serviço deve sempre buscar atender seus clientes, solucionar suas dúvidas, estar à disposição sempre que preciso e estar sempre atualizada para solucionar problemas no fornecimento do serviço.

O marketing de serviços tem características diferentes do marketing de produto, pois sua ênfase se faz no prestador de serviços, com profissionais satisfeitos, treinados e produtivos e nos clientes, que ficam satisfeitos com o desempenho de alta qualidade nos serviços e que por esse motivo se tornarão fiéis a estes profissionais.

\section{A SATISFAÇÃO DO CLIENTE}

Atualmente o consumidor tem tido maior valorização no mercado. Isso acontece pela competição acirrada das empresas e pelo fato de os consumidores estarem cada vez mais exigentes, buscando assim uma maior atenção por parte dos comerciantes.

Para Las Casas (2001, p.153), para maior satisfação dos consumidores é necessário:

Implantar uma filosofia empresarial de atendimento ao consumidor é fundamental. Se não houver uma internalização da filosofia por parte dos funcionários, com certeza não haverá condições de satisfazer consumidores. Apenas transmitir regras, sem que os funcionários estejam convencidos de agradar o cliente, não surte efeito. Na primeira oportunidade, negligenciarão os clientes.

Torna-se importante também, pesquisas no intuito de conhecer o consumidor, de saber quais são suas necessidades, do que precisa e o que realmente valoriza nos produtos ou serviços.

Para se ter avaliação do nível de satisfação do cliente, Las Casas (2001, p.155) sugere que seja feita a: 
[...] avaliação periódica do nível de satisfação dos clientes através de um questionário. Este questionário pode ser bastante variável. A empresa deve adaptar as perguntas às necessidades de cada situação. O importante é que tenha uma coluna para o item avaliado, outra para a ordem de importância e outra ainda para a avaliação final dada pelo cliente que já tenha experimentado o serviço.

Para prestação de serviço com qualidade é necessário que se conheça bem o cliente, visto que cada pessoa possui necessidades diferentes. No marketing de relacionamento existem pontos-chave, onde se pode atrair e reter clientes.

Kotler (2000, p.72) diz que "O ponto de partida são os possíveis clientes, todos aqueles que presumivelmente poderão comprar o produto ou serviço", através do conhecimento desses clientes é que a empresa passa para o próximo passo, que são os prováveis clientes potenciais, esses clientes possuem grande interesse no produto e por esse motivo estão dispostos a pagar o preço por ele.

No processo de desenvolvimento de clientes, existem também os clientes potenciais desqualificados, que são aqueles que possuem algum problema com crédito na praça ou que não são lucrativos para a empresa. Em Kotler (2000, p.72) diz "A empresa espera converter muito de seus clientes potenciais, que atendem aos requisitos, em clientes lucrativos e depois convertê-los em clientes regulares". Mas o problema é que esses dois tipos de clientes podem ainda continuar comprando na concorrência, dessa forma a empresa deve transformar esses clientes em preferenciais, que devem ser tratados com mais conhecimento. Para a empresa o desafio maior é, Kotler (2000 p.72),

[...] transformar esses clientes preferenciais em associados por meio da instituição de um programa de associação que ofereça toda uma série de benefícios aos clientes que a ele se associam. Com isso espera-se que os associados se transformem em defensores, clientes que entusiasticamente recomendam a empresa e seus produtos e serviços aos outros. O maior desafio é transformar defensores em parceiros, quando o cliente e a empresa trabalham ativamente em conjunto."

Mesmo com tantas estratégias, pode acontecer de alguns clientes se tornarem inativos ou até mesmo abandonarem a empresa, cabe a esta buscar estratégias para reconquistar esses clientes, isso se torna mais fácil pelo fato de a mesma já possuir dados, como nome e históricos desses clientes. É mais fácil trazer para a empresa ex-clientes, do que encontrar novos.

\section{METODOLOGIA}

Este trabalho foi realizado através de pesquisa censitária e descritiva e proporcionou maiores informações sobre o assunto e interpretação dos dados obtidos. Quanto à abordagem 
Estratégias promocionais utilizadas por escritórios de contabilidade de Tangará da Serra-MT para atrair clientes

Danielli Gonçalves da Cunha

Silvio Melo Gonçalves

do problema, o estudo foi do tipo quantitativo, pois utilizou-se de ferramental estatístico. Também foi utilizada a pesquisa bibliográfica, além de leituras complementares de revistas, artigos e outras publicações referentes ao tema e reuniões com o orientador para saber quais os procedimentos deveriam ser tomados para o bom desenvolvimento da pesquisa.

O universo pesquisado foram 29 escritórios de contabilidade existentes na cidade de Tangará da Serra-MT. Em 29 de Abril de 2012 foi efetuado um levantamento junto a SEFAZ do município para saber quantos escritórios de contabilidade existiam na cidade e a localização de cada um. De acordo com a SEFAZ, Tangará da Serra possui 32 escritórios ativos. Destes 32 escritórios, 29 responderam o questionário e 3 não quiseram responder, alegando estarem muito ocupados com folha de pagamento e declaração do imposto de renda.

O procedimento utilizado foi o levantamento, o qual se deu por meio de entrevista ao empresário através de um questionário contendo 16 questões com perguntas fechadas e de múltipla escolha, acerca do perfil dos contadores e a opinião deles sobre o uso do marketing.

O período de coleta dos dados, ou seja, a aplicação do questionário foi realizada entre os meses de Março a Abril de 2012.

\section{RESULTADOS E DISCUSSÕES}

Na questão quanto ao grau de instrução dos entrevistados, percebe-se que a quantidade de pessoas graduadas na área da contabilidade é expressiva, visto que se obteve percentual de $59 \%$ de pessoas graduadas, contra $14 \%$ de técnicos e $27 \%$ de pós-graduados, conforme notase na Figura 1. Com base nos dados percebe-se que a maior parte dos empresários questionados não busca se qualificar, pois somente $27 \%$ deles fizeram pós-graduação e os outros $14 \%$ só possuem nível técnico.

O profissional de contabilidade deve se manter atualizado, buscando sempre aprimorar seu conhecimento. Thomé (2001, p.75) fala sobre essa atualização do profissional contábil:

\footnotetext{
A atualização permanente é uma necessidade em quase todas as profissões. Em alguns países, ela é obrigatória e quem não cumpre certa carga horária de atualização não tem seu registro ou licença profissional renovado. São muitas as fontes onde o empresário contábil deve buscar a atualização, mas elas não são excludentes, são complementares.
}

Um profissional atualizado, com maior conhecimento, sem dúvidas tem mais credibilidade no mercado e conseguirá dessa forma um maior número de clientes. 
Figura 1: Percentual quanto ao grau de instrução dos empresários de contabilidade em Tangará da Serra-MT em 2012

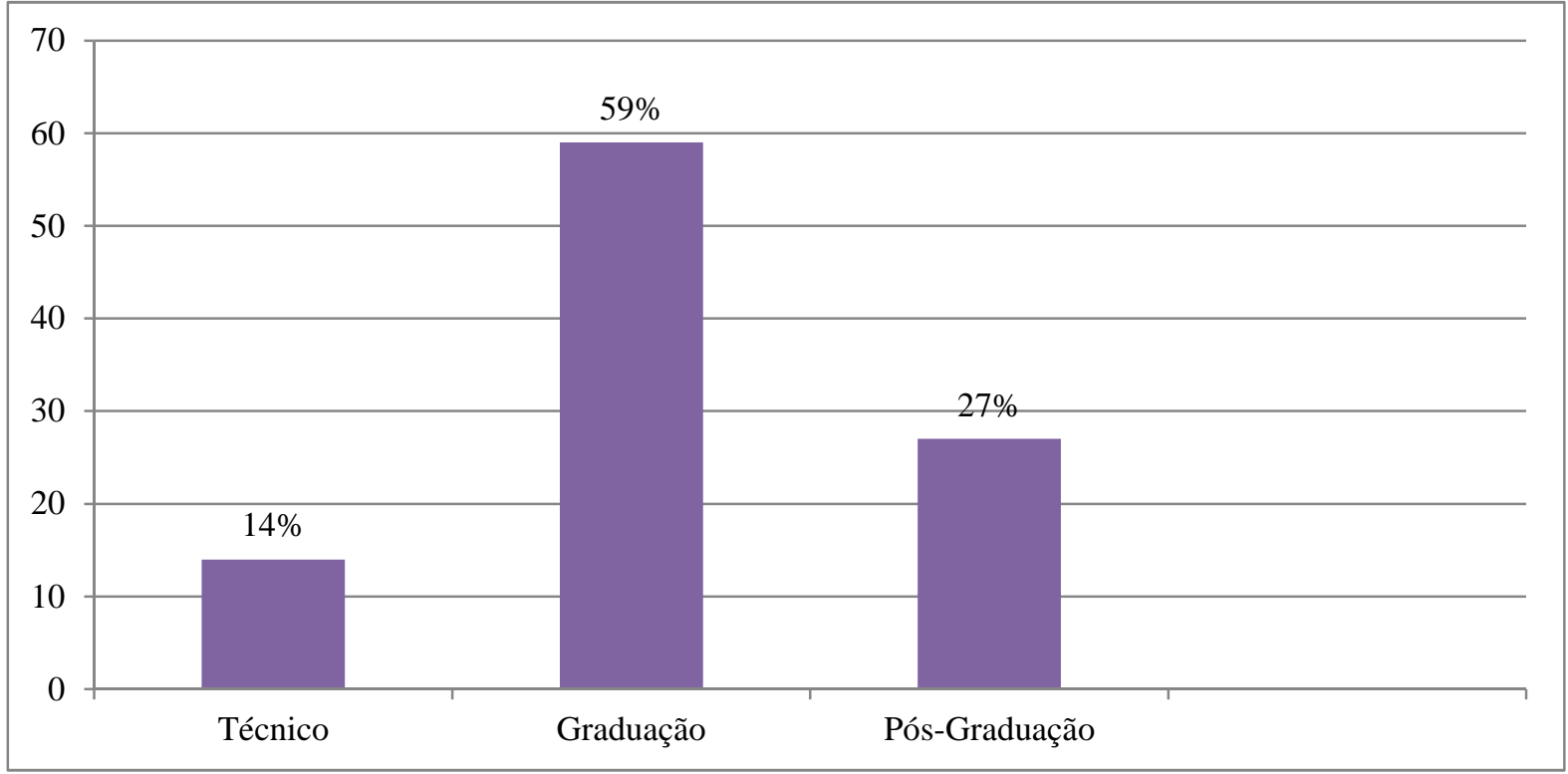

Fonte: dados da pesquisa

Quando perguntados sobre qual a forma utilizada para divulgar os escritórios, conforme Figura 2. Dos entrevistados, $2 \%$ disseram que utilizam os panfletos como forma de divulgação, $4 \%$ investem em propagandas na TV, $8 \%$ em propagandas no rádio, $12 \%$ em jornais e revistas da cidade, $6 \%$ em anúncios na internet e $56 \%$ dos entrevistados investem em brindes (canetas, calendários, agendas, chaveiros, porta-canetas, etc., com a logomarca do escritório), acreditam que esta é a melhor estratégia de promoção, pois através da exposição desses brindes nas empresas de seus clientes que atingirão novos possíveis clientes para seus escritórios. Urdan e Urdan (2009, p.315) falam sobre o uso do brinde:

Procura induzir a venda de um produto, oferecendo outro produto. Os brindes atendem ao desejo de levar algo mais na transação. Mesmo o pequeno brinde cria interesse se é prático, original ou exclusivo. Se a marca é estampada no brinde, o consumidor mantém contato com ela por longo tempo, como acontece com uma caneta ou chaveiro. $\mathrm{O}$ brinde estimula a experimentação de novo produto.

Assim como os brindes, os outros meios de comunicação também são de grande importância. A televisão, por exemplo, consegue atingir consumidores de vários cantos do 
Estratégias promocionais utilizadas por escritórios de contabilidade de Tangará da Serra-MT para atrair clientes

Danielli Gonçalves da Cunha

Silvio Melo Gonçalves

país. O custo desse meio é elevado, mas devido à grande cobertura, o investimento se torna viável. A promoção através do rádio, assim como cita Urdan e Urdan (2009, p.285) “[...] é simples e barata e o comercial fica acessível a empresas com orçamentos promocionais reduzidos. É possível conceber e veicular o anúncio com rapidez, em dias ou mesmo horas".

O jornal, pelo fato de ter uma maior circulação, proporciona ao anunciante agilidade para veicular suas mensagens, além da praticidade, que é confirmada por Urdan e Urdan (2009, p.286) "O jornal permite textos bem completos na propaganda e o leitor tem boa habilidade com informações escritas. O jornal de prestígio dá certa credibilidade à marca anunciada".

Ainda dentro dessa questão, $12 \%$ dos entrevistados apostam em outras formas de abordagem ao possível cliente, entre estas se destaca a indicação, segundo alguns empresários a indicação do serviço feita pelos seus clientes para outras pessoas também se torna uma boa estratégia de marketing. Segundo Kotler e Armstrong (2003, p.3), o marketing é "um processo administrativo e social pelo qual indivíduos e grupos obtêm o que necessitam e desejam, por meio da criação, oferta e troca de produtos e valor com os outros". O marketing neste caso acaba ajudando o empresário a conhecer e entender os desejos dos clientes e dessa forma criar serviços adequados e satisfatórios.

Todas as estratégias promocionais possuem suas vantagens e desvantagens. Cabe ao empresário encontrar a que melhor se adequa a seu estabelecimento e que transmita a mensagem ao público-alvo com mais eficiência e eficácia.

Figura 2: Percentual das ações realizadas para promoção dos escritórios de contabilidade em Tangará da Serra-MT em 2012 
Estratégias promocionais utilizadas por escritórios de contabilidade de Tangará da Serra-MT para atrair clientes

Danielli Gonçalves da Cunha

Silvio Melo Gonçalves

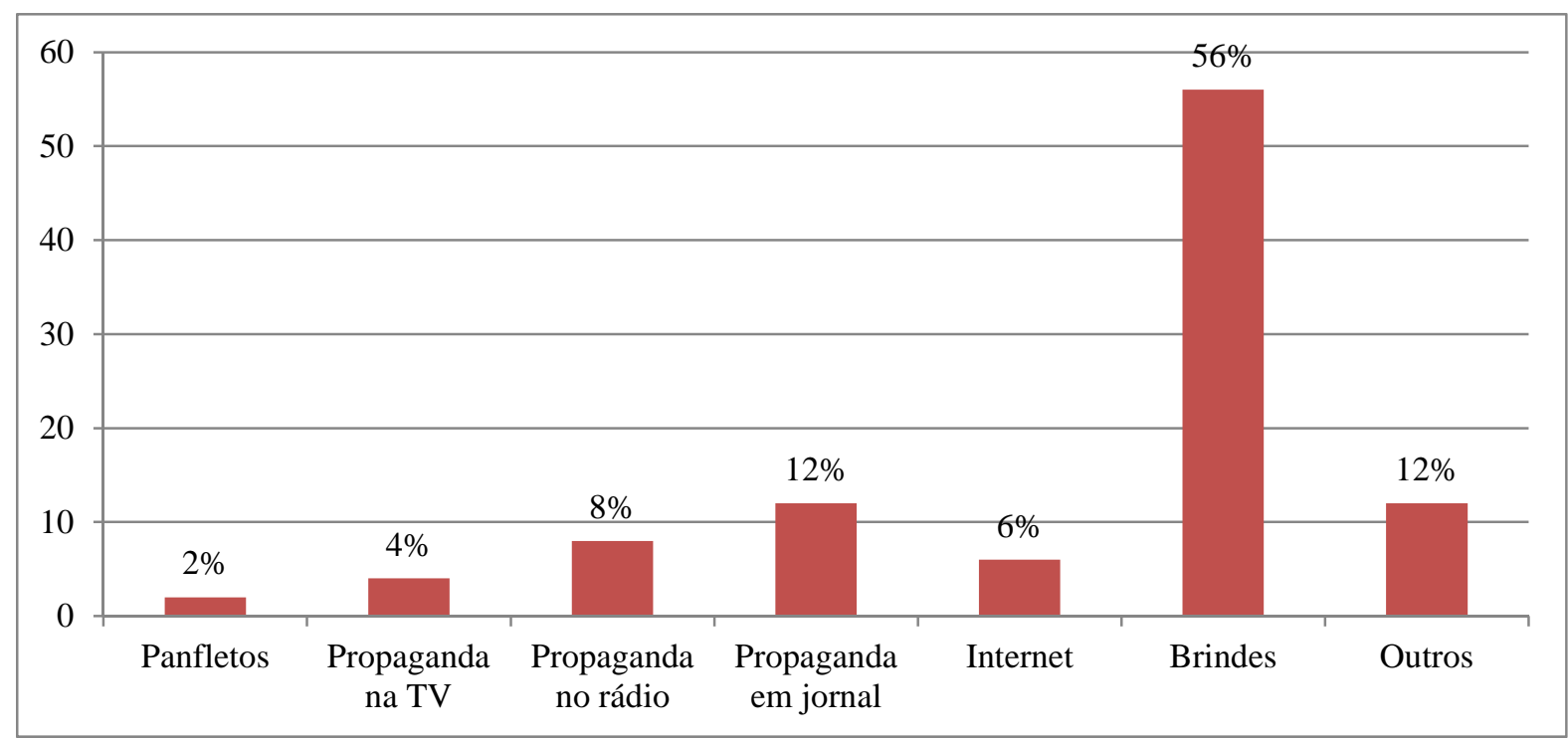

Fonte: dados da pesquisa

Diante de tantas estratégias promocionais utilizadas pelos escritórios de contabilidade, foi questionado aos entrevistados se os mesmos realizavam pesquisas para saber se a promoção surtiu efeito. Na Figura 3 é possível ver que $24 \%$ das pessoas responderam que sim e 76\% disseram que não. Segundo os empresários que responderam não realizar pesquisas, a melhor forma de analisar se a promoção foi satisfatória é através do aumento de clientes procurando os serviços de seu estabelecimento.

Figura 3: Percentual dos escritórios de Contabilidade de Tangará da Serra-MT em 2012 sobre a realização de pesquisas para saber se a promoção surtiu efeito.

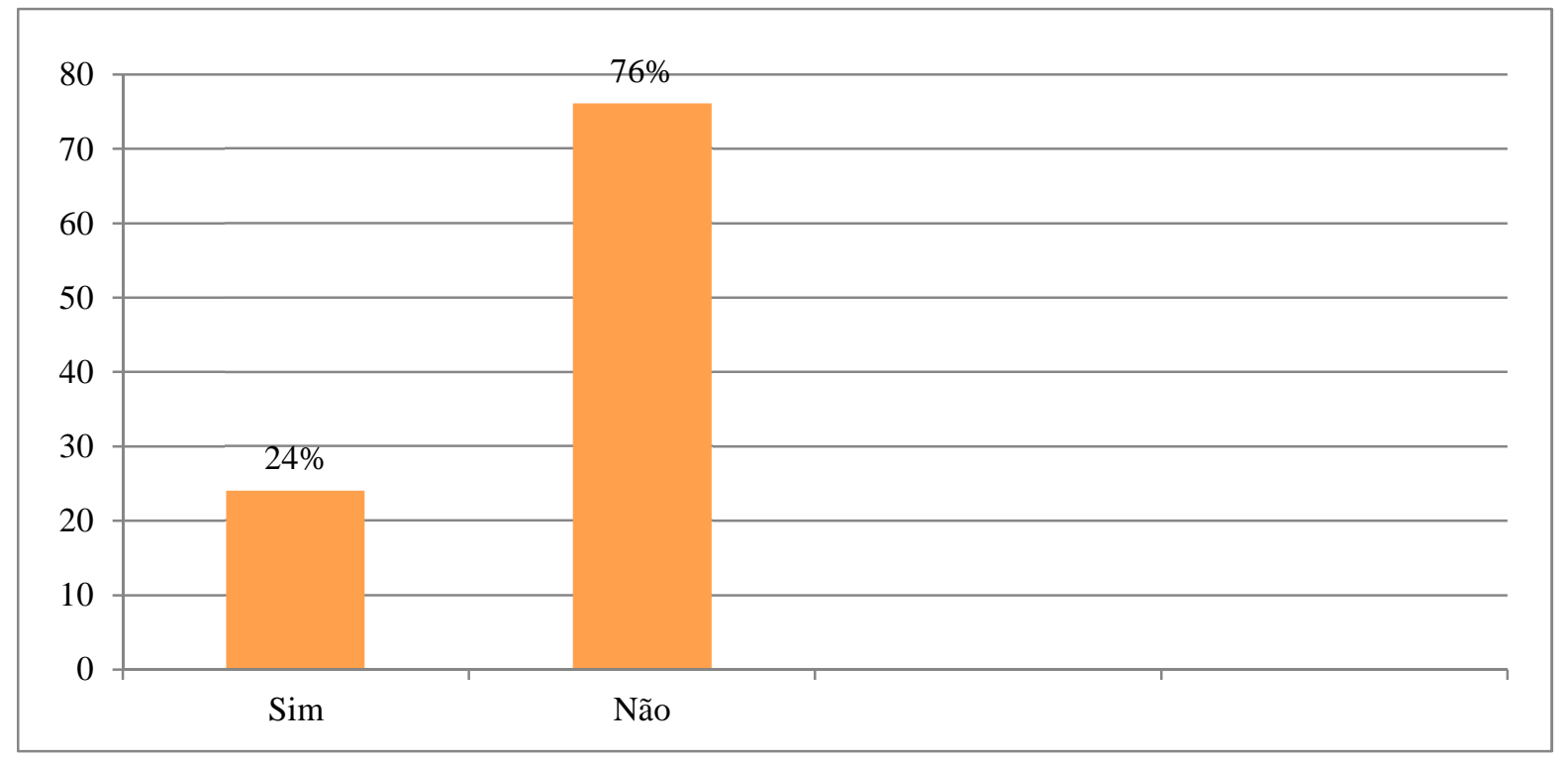

Fonte: dados da pesquisa

Quando perguntado aos empresários se eles acham que o investimento em propaganda se torna um diferencial no ramo da contabilidade, $62 \%$ deles responderam que sim e $38 \%$ 
Estratégias promocionais utilizadas por escritórios de contabilidade de Tangará da Serra-MT para atrair clientes

Danielli Gonçalves da Cunha

Silvio Melo Gonçalves

disseram que não, conforme Figura 4. Os empresários entendem que esse investimento é importante para o escritório, mas a maioria não aplica os recursos de maneira correta no marketing. Para os entrevistados, o marketing se restringe à propaganda, às vezes feita de maneira superficial e desordenada. Na opinião dos empresários que optaram pela alternativa "não”, o que mais vale nesta área é a indicação.

A solução para essa questão seria a contratação de profissionais especializados na área do marketing, que saberiam aplicar os recursos de forma correta, visando atender as necessidades dos clientes e buscando sempre o sucesso da empresa.

Figura 4: Percentual dos entrevistados sobre se acham que o investimento em propaganda é um diferencial no ramo de atividade em que atuam na cidade de Tangará da Serra-MT em 2012

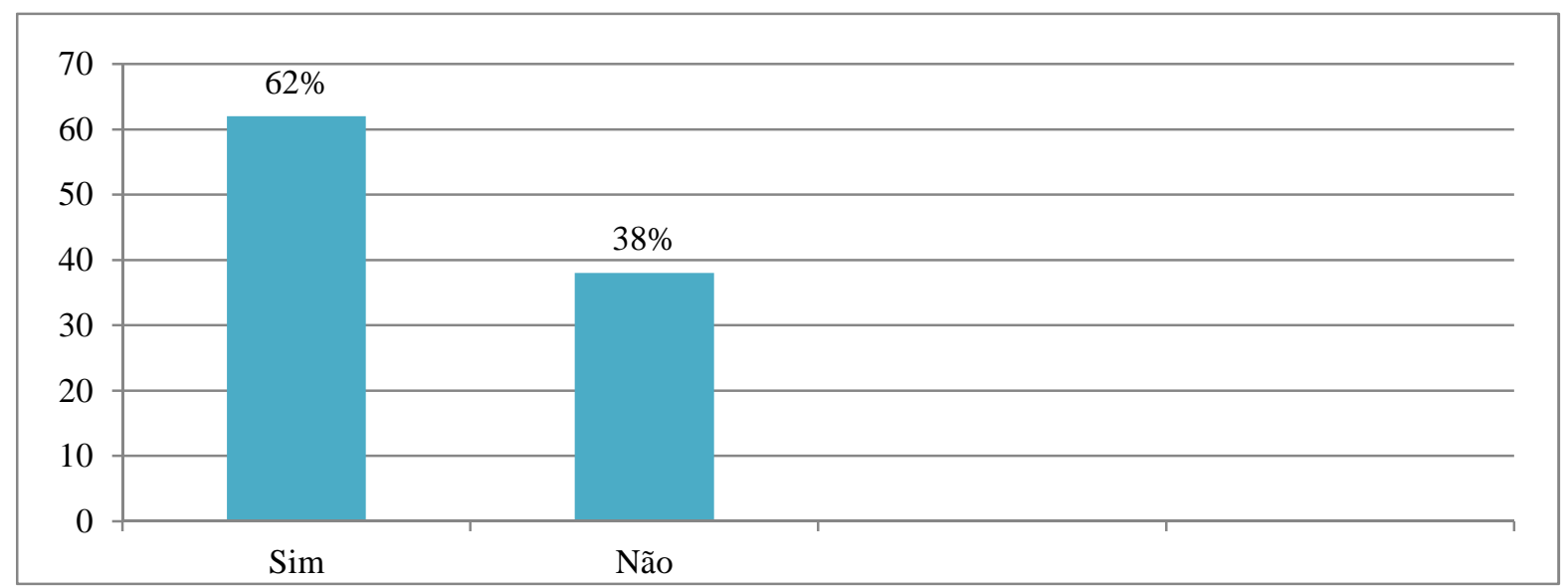

Fonte: dados da pesquisa

Os empresários foram questionados sobre conhecer o perfil de seus clientes, Figura 5. 97\% dos entrevistados disseram que sim, conhecem o perfil de todos os seus clientes e $3 \%$ diz que não. Além de conhecer o perfil do cliente é importante também que o empresário realize pesquisas, no intuito de saber quais são suas necessidades, do que ele precisa e o que realmente valoriza em um produto ou serviço. 
Figura 5: Percentual dos entrevistados em relação ao conhecimento do perfil de seus clientes em Tangará da Serra-MT em 2012

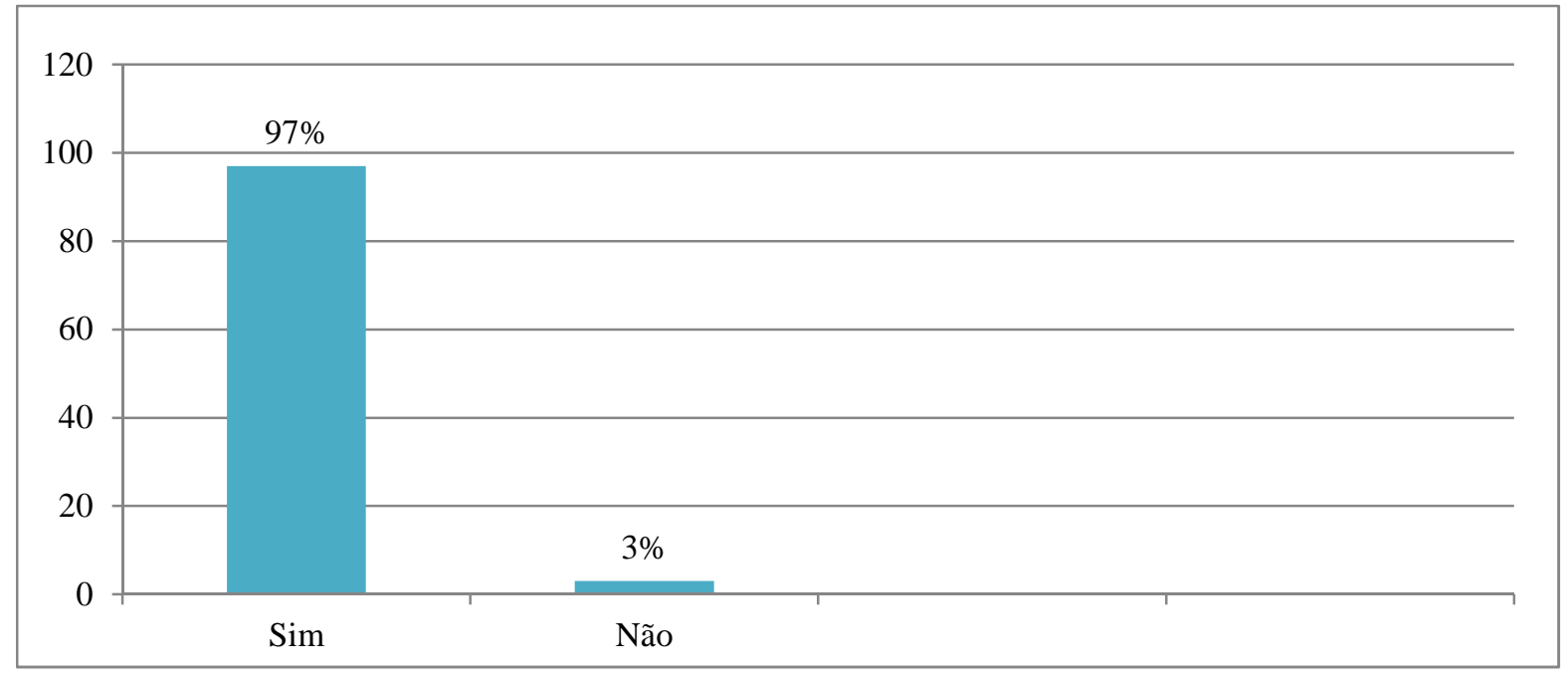

Fonte: dados da pesquisa

A Figura 6 vem demonstrar com que frequência os entrevistados visitam seus clientes. $13 \%$ das pessoas disseram que visitam seus clientes toda semana, 23\% visitam mensalmente, $7 \%$ só vão até seus clientes anualmente e $57 \%$ só realizam visitas quando é necessário. Esta sem dúvida é uma das questões mais preocupantes, pois nota-se aqui um descaso por parte dos empresários, quando a grande maioria respondeu que só visita seus clientes quando é necessário, ou seja, eles não se preocupam com o que acontece diariamente nas empresas em que prestam serviços. Outro ponto que vale salientar é que nenhum dos entrevistados escolheu a opção de visitar seus clientes “todos os dias". É necessário que o empresário vá até o estabelecimento de seu cliente. A visita ao cliente demonstra interesse e mostra como ele é importante para o contador e para seu escritório.

A presença do empresário no estabelecimento de seu cliente aumentará sua confiança e permitirá a criação de maiores vínculos, através da amizade que se desenvolverá ao longo do relacionamento comercial, além de agilizar o processo na tomada de decisão. Com essa atitude, o cliente se sentirá importante e sem dúvida será uma excelente oportunidade para o empresário conhecer a imagem que o cliente tem do seu escritório.

Figura 6: Percentual dos entrevistados sobre a frequência que visitam seus clientes, em Tangará da Serra-MT em 2012 
Estratégias promocionais utilizadas por escritórios de contabilidade de Tangará da Serra-MT para atrair clientes

Danielli Gonçalves da Cunha

Silvio Melo Gonçalves

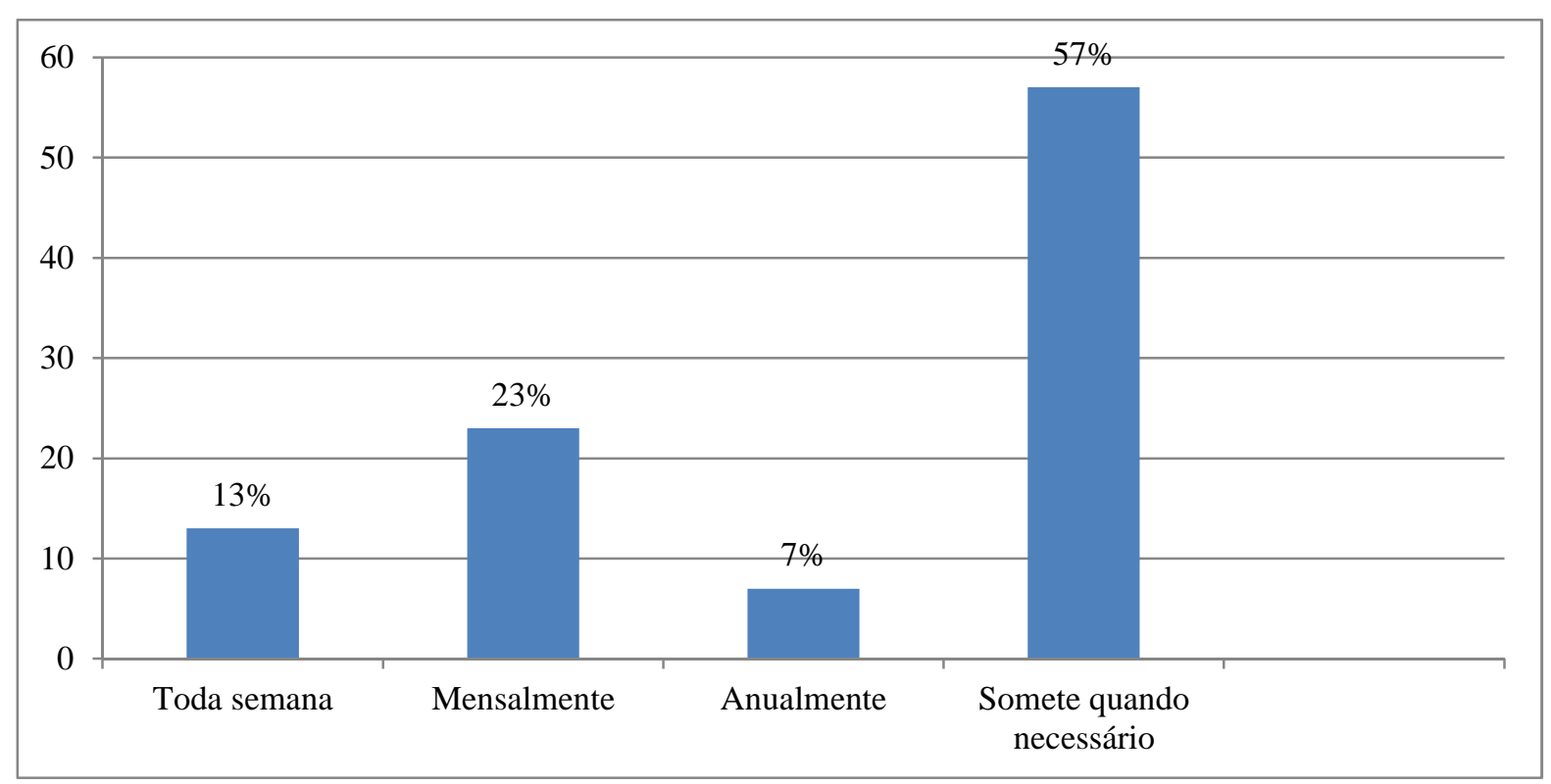

Fonte: dados da pesquisa

A Figura 7 mostra os serviços que são oferecidos pelos escritórios de contabilidade dos entrevistados. $31 \%$ dos escritórios prestam serviço na área da Contabilidade Fiscal, $21 \%$ na área de Contabilidade Gerencial, 30\% prestam serviços de Folha de pagamento, 4\% prestam auditoria, $11 \%$ atuam na consultoria financeira, $1 \%$ oferece serviços na área de pesquisa de mercado e $2 \%$ atuam em outras áreas, como Perícia e Rural.

Figura 7: Percentual dos entrevistados sobre os serviços oferecidos pelos escritórios de contabilidade em Tangará da Serra-MT em 2012

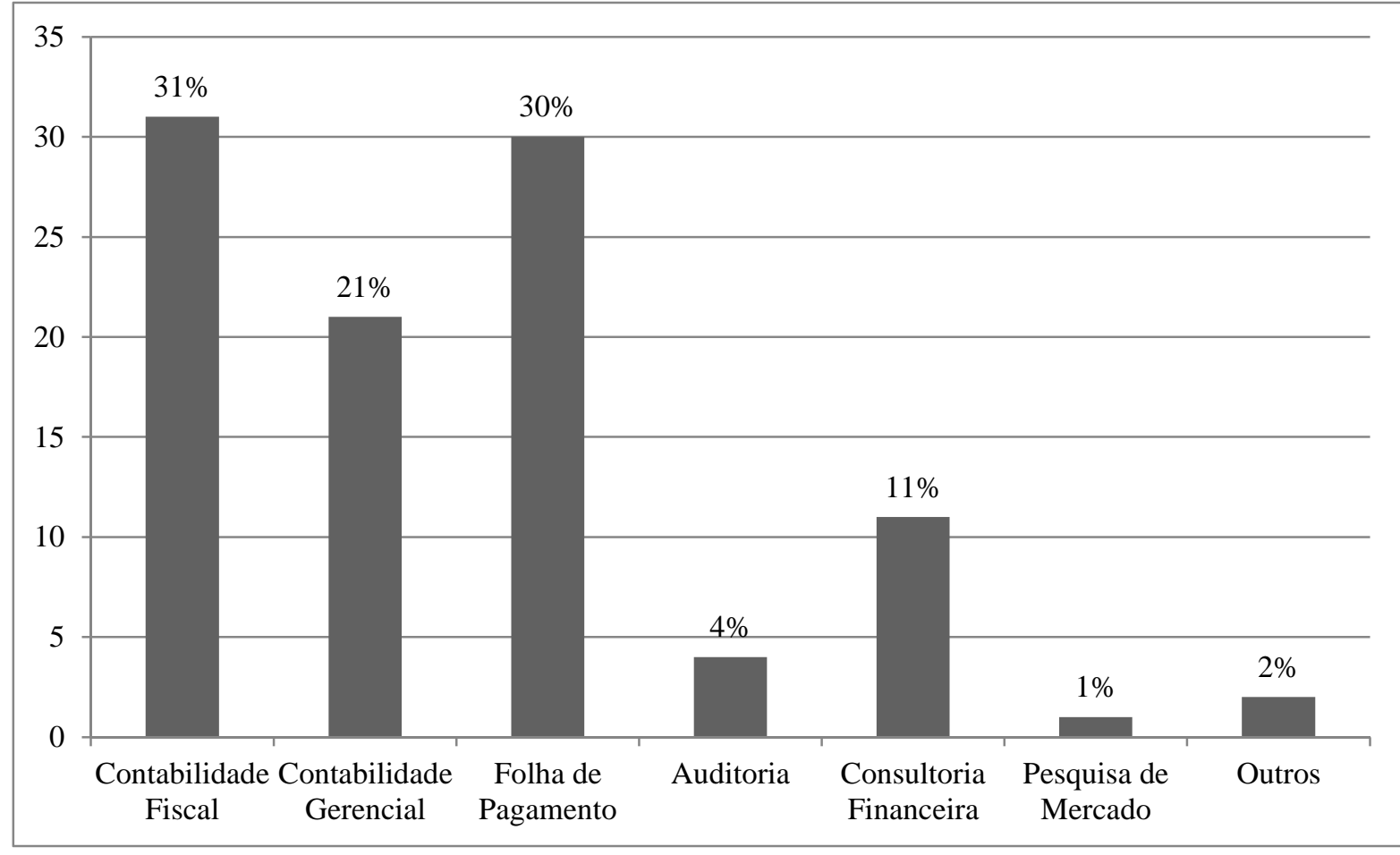


Estratégias promocionais utilizadas por escritórios de contabilidade de Tangará da Serra-MT para atrair clientes

Danielli Gonçalves da Cunha

Silvio Melo Gonçalves

Os entrevistados foram questionados, Figura 8 , se já realizaram alguma pesquisa de mercado para saber como seu escritório é visto pela sociedade. $10 \%$ responderam que sim, já realizaram algumas pesquisas e $90 \%$, ou seja, a maioria nunca realizou nenhum tipo de pesquisa. O problema aqui pode ser o ambiente de marketing, que segundo Kotler e Armstrong (2000, p.39) consiste em "fatores e forças externas ao marketing que afetam a capacidade da administração de marketing de desenvolver e manter relacionamentos bemsucedidos com seus clientes-alvo". Para solucionar esse problema o escritório pode contratar serviços de profissionais de marketing que terão a responsabilidade de identificar mudanças para o ambiente, assim como coletar o maior número de informações possíveis sobre o mercado visando novas oportunidades.

Figura 8: Percentual dos empresários contábeis sobre terem realizado alguma pesquisa de mercado em Tangará da Serra-MT em 2012

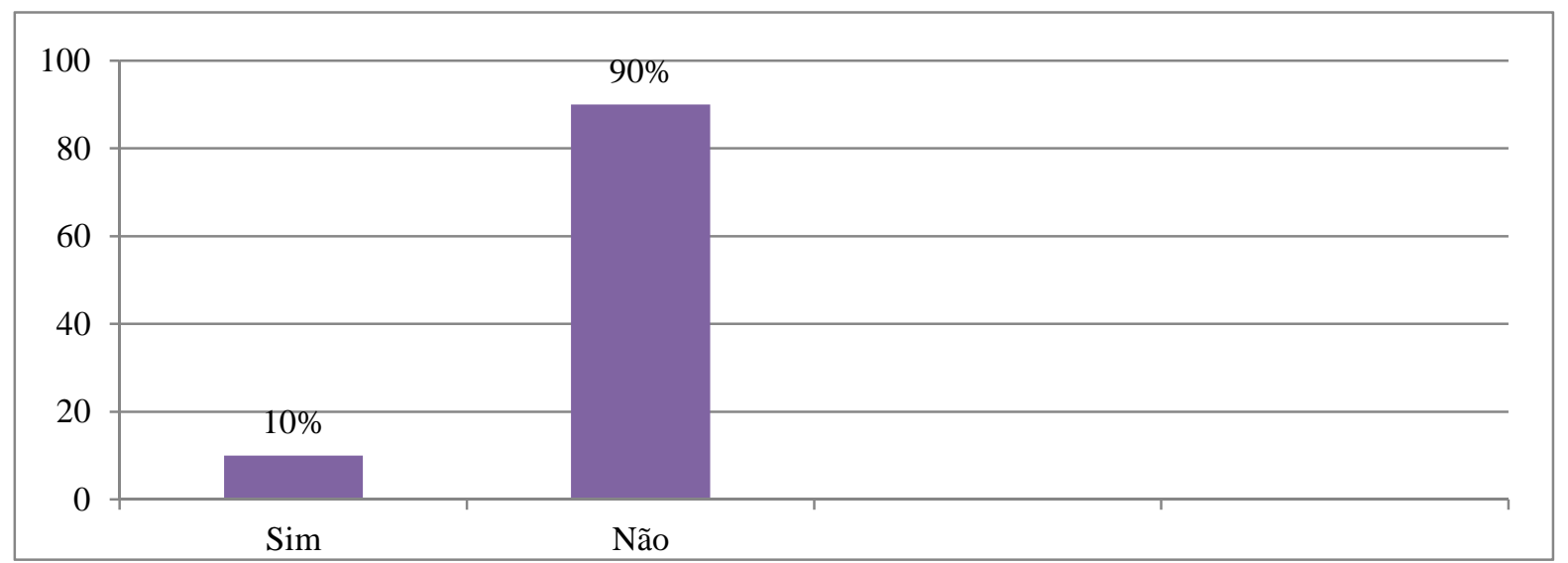

Fonte: dados da pesquisa

Também foi perguntado aos entrevistados, se eles já realizaram alguma pesquisa para verificar a satisfação de seus clientes quanto aos serviços prestados. $28 \%$ disseram que sim, mas $72 \%$ disseram que nunca fizeram nenhum tipo de pesquisa, conforme Figura 9, mostrando dessa forma certo descaso com relação à opinião de seus clientes.

Estar preparado para atender satisfatoriamente o cliente é essencial para qualquer negócio. Na prestação de serviços isso se torna ainda mais importante, já que impressões negativas relacionadas com serviços prestados, tem relação direta com a imagem que a marca da empresa passa para o mercado. Por isso para conseguir atender e superar as expectativas dos clientes é necessário primeiramente conhecê-los. 
Estratégias promocionais utilizadas por escritórios de contabilidade de Tangará da Serra-MT para atrair clientes

Danielli Gonçalves da Cunha

Silvio Melo Gonçalves

Figura 9: Percentual de entrevistados sobre terem realizado alguma pesquisa para verificar a satisfação de seus clientes em Tangará da Serra-MT em 2012

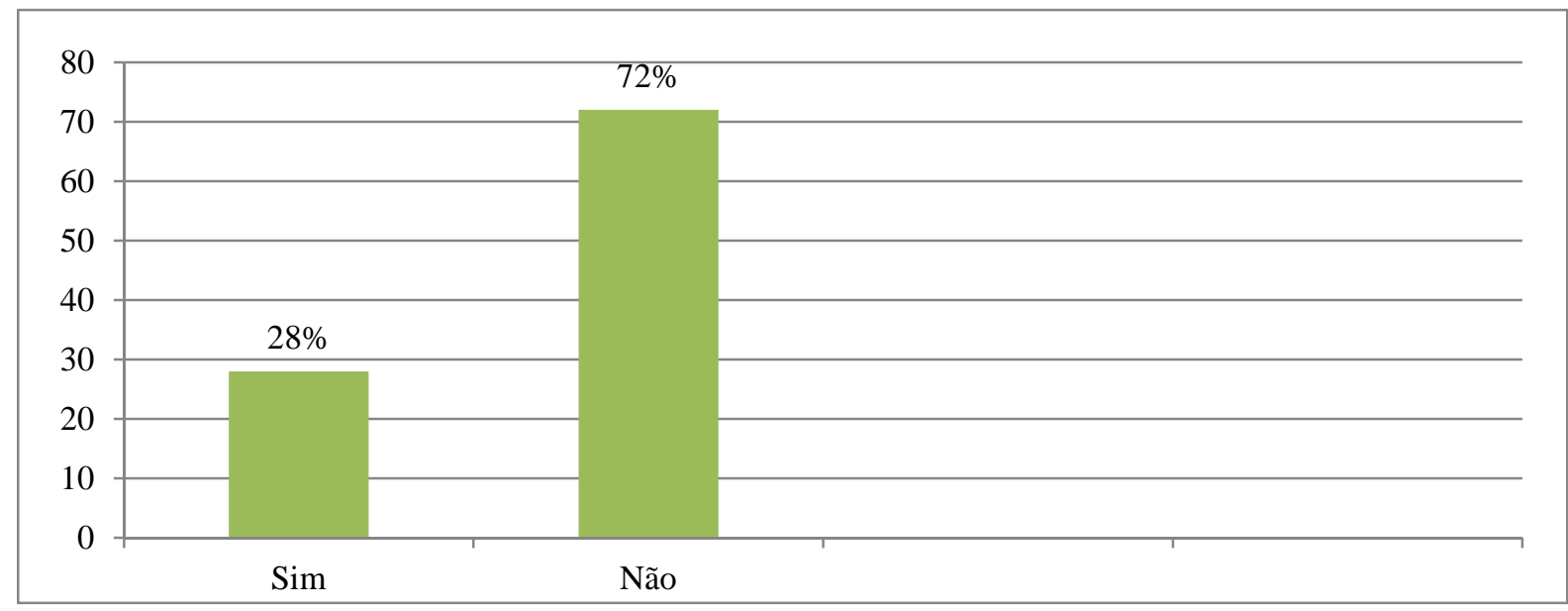

Fonte: dados da pesquisa

\section{CONCLUSÃO}

Através da pesquisa realizada se obteve a resposta do problema levantado para este artigo: "Estratégias promocionais utilizadas por escritórios de contabilidade de Tangará da Serra-MT para atrair clientes". Foram levantadas duas hipóteses para este problema. A primeira de que os escritórios utilizavam-se dos meios de comunicação (televisão, rádio, jornais) para promoção de seus serviços e a segunda de que os escritórios de contabilidade não possuem estratégias promocionais. Na verdade as duas hipóteses foram confirmadas, pois segundo a análise dos resultados $4 \%$ dos entrevistados disseram utilizar propagandas na TV como forma de promoção, $8 \%$ utilizam o rádio e $12 \%$ fazem divulgação através de revistas e jornais. Somando todos esses resultados, chega-se ao total de $24 \%$ de pessoas que se encaixam na hipótese 1(um) deste artigo.

A maioria, total de $56 \%$ dos entrevistados, disseram utilizar os brindes como forma de promoção. Segundo alguns empresários, no ramo da contabilidade a propaganda não se torna tão importante, visto que o que vale mais é a experiência do contador e as indicações feitas por clientes do escritório, por isso é que muitos não possuem estratégias promocionais concretas. Por esse motivo é que se pode notar, através dos resultados, que eles não buscam fazer pesquisas para saber se o investimento em propaganda surtiu efeito.

A confecção de brindes, segundo os entrevistados, é uma forma de presentear os clientes e amigos, e com isso também acabar promovendo o seu escritório através dessas pessoas, pois com a exposição desses materiais novos clientes serão alcançados. 
Estratégias promocionais utilizadas por escritórios de contabilidade de Tangará da Serra-MT para atrair clientes

Danielli Gonçalves da Cunha

Silvio Melo Gonçalves

Como sugestão, fica a dica para que os empresários da contabilidade busquem ter mais contato com seus clientes, através de visitas, pois na pesquisa obteve-se percentual onde $57 \%$ dos entrevistados disseram só visitar seus clientes quando é necessário. Isso faz com que se chegue à conclusão de que eles esperam o cliente vir com o problema até eles, ou seja, espera o problema acontecer. Fato que não ocorreria se o empresário mantivesse um contato permanente com seus clientes. Até porque conhecer bem o perfil, suas necessidades e seus problemas, acaba facilitando na tomada de decisões. Para reforçar essa afirmação Drucker (1999) cita que "O relacionamento com o cliente é de responsabilidade da empresa. Qualquer reclamação ou conflito por parte do cliente é provocado por uma falha empresarial". E continua, “A empresa deve perguntar-se constantemente o que pode ser feito para facilitar e melhorar a vida de seus clientes". De acordo com Terry (1993, p.255):

[...] os relacionamentos bem-sucedidos com clientes exigem prática constante e intensas técnicas de pós-marketing. Um dos esforços mais evidentes é a coleta de informações a respeito dos clientes, também é sugerida como atividade de pósmarketing a elaboração de um programa de mensuração da satisfação do cliente. Tal programa fornece um feedback do cliente referente à qualidade dos produtos ou serviços e sugere caminhos para futuras mudanças e melhorias.

Além do bom relacionamento com o cliente, os empresários podem investir mais no marketing dentro dos escritórios, através da abertura de um departamento específico colocando como encarregado uma pessoa com experiência nessa área, ou até mesmo a contratação de uma empresa especializada, que monte estratégias e planos com o intuito de promover o escritório e os serviços prestados.

O sucesso de uma empresa depende da satisfação de seus clientes. E a felicidade desses clientes não depende apenas do atendimento recebido pelo escritório, mas também da qualidade do serviço e do compromisso deste em entregar o prometido no prazo. Clientes satisfeitos permanecem realizando serviços na empresa, além de indicar a mesma a outras pessoas, esta é a famosa propaganda "boca-a-boca" que é muito eficiente e não possui nenhum custo.

\section{REFERÊNCIAS BIBLIOGRÁFICAS}

BLESSA, Regina. Merchandising no ponto de venda. São Paulo. Atlas, 2001.

CONSELHO FEDERAL DE CONTABILIDADE. Código de ética profissional do contabilista CEPC. Disponível

em:<http://www.portaldecontabilidade.com.br/legislacao/cepc.htm> acesso em: 25/04/2011 
Estratégias promocionais utilizadas por escritórios de contabilidade de Tangará da Serra-MT para atrair clientes

Danielli Gonçalves da Cunha

Silvio Melo Gonçalves

DRUCKER, Peter F. Administrando em tempos de grandes mudanças. São Paulo.

Pioneira, 1999.

KOTLER, Philip. Administração de marketing: a edição do novo milênio. São Paulo. Prentice Hall, 2000.

KOTLER, Philip; ARMSTRONG, Gary. Introdução ao marketing. Rio de Janeiro. 4 ed. LTC editora, 2000.

,Princípios de marketing. São Paulo. 9 ed. Prentice Hall, 2003.

LAS CASAS, Alexandre Luzzi. Marketing. São Paulo. 3 ed. Atlas, 1994.

, Marketing. São Paulo. 5 ed. Atlas, 2001.

, Marketing de serviços. São Paulo. 3 ed. Atlas, 2002.

LOVELOCK, Christopher; WRIGHT, Lauren. Serviços marketing gestão. São Paulo.

Saraiva, 2003.

PELEIAS, Ivan Ricardo; HERNANDES, Danieli Cristina Ramos; GARCIA, Mauro Neves; SILVA, Dirceu da. Marketing contábil nos escritórios de contabilidade do Estado de São Paulo. RBGN, São Paulo, Vol. 9, n. 23, p. 61-77, jan/abr 2007.

<http://www.portaldomarketing.com.br/Artigos/Marketing\%20de\%20servicos.htm>acesso em: 08/05/2011

<http://pt.wikipedia.org/wiki/Marketing_de_relacionamento> acesso em: 08/04/2012

TERRY G. Vavra, Marketing de relacionamento. São Paulo. Ed Atlas, 1993.

THOMÉ, Irineu. Empresa de serviços contábeis: estrutura e funcionamento. São Paulo. Atlas, 2001.

URDAN, Flávio Torres; URDAN, André Torres. Gestão do composto de marketing. São Paulo. 1 ed. Atlas, 2009. 